\title{
Prevention of Surgical Site Infections in Gynecologic Surgery: A Review of Risk Factors and Recommendations
}

\author{
Veronica Gillispie-Bell, MD, MAS \\ Department of Obstetrics and Gynecology, Ochsner Clinic Foundation, New Orleans, LA and The University of Queensland Faculty of \\ Medicine, Ochsner Clinical School, New Orleans, LA
}

Background: Surgical site infections (SSIs) are a type of health care-associated infection that can cause significant patient harm. Many are preventable. Postoperative courses complicated by an SSI can equate to longer hospital stays, lost time from work, and the need for reoperation.

Methods: This review addresses types of SSIs, risk factors, and best practices for preventing SSIs associated with gynecologic surgery.

Results: Best practices to reduce SSIs are divided into preoperative, intraoperative, and postoperative activities. Preoperative considerations include patient showering, hair removal, glycemic control, and hand and forearm scrub. Intraoperative concerns are antibiotic prophylaxis, skin preparation prior to the start of surgery, and the operating room environment. Postoperative concerns are surgical dressing, vacuum-assisted wound closure, and patient instructions.

Conclusion: Best practices should be established and followed to reduce the risk of SSI associated with gynecologic surgery.

Keywords: Gynecologic surgical procedures, quality improvement, risk factors, surgical wound infection

Address correspondence to Veronica Gillispie-Bell, MD, MAS, Department of Obstetrics and Gynecology, Ochsner Baptist Hospital, 4429 Clara St., Ste. 540, New Orleans, LA 70115. Tel: (504) 842-9620. Email: vgillispie@ochsner.org

\section{INTRODUCTION}

Surgical site infections (SSIs) are a type of health careassociated infection that can cause significant patient harm. Postoperative courses complicated by an SSI can equate to longer hospital stays, lost time from work, and the need for reoperation. Data from 2009 demonstrate that hospital stays were extended an average of 9.7 days because of SSls, with an average cost of $\$ 20,842$ per hospital stay. ${ }^{1}$ A study conducted at The Johns Hopkins Hospital during a 3-year period found an SSI rate of 2.76 per 100 surgical procedures, resulting in a net loss in profit between $\$ 4,147$ and $\$ 22,239$ per SSI. $^{2}$ According to the Centers for Disease Control and Prevention (CDC), the mortality rate associated with $\mathrm{SSI}$ is $3 \%{ }^{3}$ However, with the use of best practices, $40 \%$ to $60 \%$ of SSIs are preventable. ${ }^{4}$ The cost to hospital facilities combined with the high preventability has led many hospital systems to use SSI rate as a value-based metric.

\section{CLASSIFYING A SURGICAL SITE INFECTION}

The CDC and the National Healthcare Safety Network have clear definitions for the 3 categories of SSIs that occur within 30 days after a procedure: superficial, deep, and organ space (Table 1). ${ }^{3}$ A superficial SSI is confined to the skin or subcutaneous tissue, a deep SSI involves deep soft tissue, and an organ space SSI involves a body part that is below the fascia.

\section{RISK FACTORS}

Risk factors for SSIs can be divided into 2 groups: patient risk factors and operative risk factors (Table 2).

\section{Patient Risk Factors}

According to the American College of Surgeons, patients who are active smokers have a $40 \%$ higher risk of postoperative surgical complications, including $\mathrm{SSI},{ }^{5}$ because of vasoconstriction that leads to tissue hypoxia. Additionally, smoking alters the immune response. Because of the significant risk for postoperative complication, the American College of Surgeons recommends that patients stop smoking for at least 4 to 6 weeks prior to surgery.

Obesity is also an independent risk factor for developing an SSI, particularly for patients undergoing abdominal surgeries such as hysterectomy. ${ }^{6}$ The pathophysiology of obesity and the increased risk of SSI is thought to be attributed to the increased ratio of adipose tissue to capillary density, which leads to poor tissue perfusion. Because of the increased risk of SSI with obesity, appropriate weight-based preoperative antibiotics should be administered to reduce the risk.

\section{Operative Risk Factors}

Longer surgery duration, even with appropriate redosing of antibiotics, has been identified as an independent risk factor for developing an SSI. ${ }^{7}$ Intraoperative blood transfusion also increases the risk of SSI, especially for organ 
Table 1. Categories of Surgical Site Infections ${ }^{3}$

\begin{tabular}{|c|c|c|}
\hline Category & Affected Tissue & Characteristics \\
\hline Superficial & $\begin{array}{l}\text { Superficial tissue, skin, } \\
\text { and subcutaneous } \\
\text { tissue }\end{array}$ & $\begin{array}{l}\text { One of the following required: } \\
\text { Purulent drainage } \\
\text { Organism appropriately obtained through wound culture } \\
\text { Incision opened by physician, surgeon, or advanced practice practitioner and presence } \\
\text { of pain, swelling, warmth, or redness } \\
\text { Diagnosed as a superficial surgical site infection by a physician, surgeon, or advanced } \\
\text { practice practitioner }\end{array}$ \\
\hline Deep & $\begin{array}{l}\text { Deep tissue, fascia, or } \\
\text { muscle }\end{array}$ & $\begin{array}{l}\text { One of the following required: } \\
\text { Purulent drainage } \\
\text { Spontaneous dehiscence or incision opened by a surgeon, organism appropriately } \\
\text { obtained through wound culture, and presence of pain or fever } \\
\text { Abscess identified by examination, surgery, or imaging }\end{array}$ \\
\hline Organ space & $\begin{array}{l}\text { Below the fascia and } \\
\text { muscle }\end{array}$ & $\begin{array}{l}\text { One of the following required: } \\
\text { Purulent drainage from a drain in the deep organ space } \\
\text { Organism appropriately obtained through wound culture } \\
\text { Abscess identified by examination, surgery, or imaging }\end{array}$ \\
\hline
\end{tabular}

space infections. ${ }^{8}$ Wound classification is another operative risk factor. The CDC classifies operative procedures and their wounds as clean, clean-contaminated, contaminated, or dirty/infected (Table 3 ). ${ }^{3}$ Hysterectomy is classified as a clean-contaminated procedure. In general, cleancontaminated procedures have an infection rate of $3.94 \%$; the aim of best practices is to lower this rate. ${ }^{9}$

\section{BEST PRACTICES TO REDUCE SURGICAL SITE INFECTION}

Best practices to reduce SSIs are divided into preoperative, intraoperative, and postoperative activities.

\section{Preoperative Considerations}

Patient Showering. Patients should shower with soap or an antiseptic agent at least the night before surgery. While preoperative showering has been shown to reduce the rate of SSIs, a 2015 Cochrane review demonstrated no benefit to showering with bar soap vs chlorhexidine. ${ }^{10}$ However, the data showed a statistically significant reduction in SSIs after a full wash with chlorhexidine vs a partial wash. Of note, the method by which the wash was performed was not standardized in the studies included in the Cochrane review. Another study published in the Journal of the American Medical Association showed a reduction in SSls when the wash was standardized: a minimum of 2 sequential showers and a 1-minute pause before rinsing. ${ }^{11}$ Given the variations in studies and the lack of conclusive data, the literature does not

Table 2. Risk Factors for Surgical Site Infections

\begin{tabular}{ll}
\hline Patient Risk Factors & Operative Risk Factors \\
\hline Smoking & Length of surgery \\
Diabetes & Blood transfusion \\
Obesity & Wound classification (clean, \\
Malnutrition & clean-contaminated, \\
Anticoagulation & contaminated, dirty/infected) \\
Presence of infection & \\
Age & \\
\hline
\end{tabular}

provide consensus on how the shower should be performed or what type of cleanser should be used.

Hair Removal. Patients should be instructed to not remove hair at home prior to surgery. For surgical purposes, hair should not be removed unless it will interfere with the procedure. If hair needs to be removed, clippers instead of a razor should be used because razors can cause microtrauma to the skin that can be a nidus of infection. Preoperative nurses should be instructed to make the hair lower but not to make the area bald, because making an area bald can also cause microtrauma to the skin. Hair should be removed in the preoperative area and not the operating room. ${ }^{1}$

Glycemic Control. The stress of surgery causes dysregulation in glucose production and glucose utilization, thereby increasing the risk of SSI. From $12 \%$ to $30 \%$ of patients undergoing surgery are found to have hyperglycemia, even in the absence of a history of diabetes. ${ }^{12}$ Therefore, performing a fasting blood sugar test on all patients prior to surgery, regardless of their history of diabetes, is important. The target glucose level is debatable. The Society for Ambulatory Anesthesia, ${ }^{13}$ the American Diabetes Association/American Association of Clinical Endocrinologists, ${ }^{14}$ the Endocrine Society, ${ }^{15}$ and the Society of Thoracic Surgeons ${ }^{16}$ all recommend a glucose level $<180 \mathrm{mg} / \mathrm{dL}$, while the CDC recommends preoperative glucose $<200 \mathrm{mg} / \mathrm{dL}$ to reduce the risk of SSI. ${ }^{17}$ Based on data from critically ill patients in intensive care units, glucose $<110 \mathrm{mg} / \mathrm{dL}$ is associated with adverse outcomes and should be avoided as well. ${ }^{18}$

Hand and Forearm Scrub. The traditional 10-minute hand and forearm scrub is no longer recommended. Scrubbing for 2 to 6 minutes is just as effective for reducing bacteria without the skin damage that can result from the 10-minute scrub. ${ }^{19}$ Either an antimicrobial soap or an alcohol-based scrub should be used with or without a sponge but not with a brush. Alcohol-based scrubs provide an immediate antimicrobial effect because of the denaturation of proteins and are effective against most gram-positive and gram-negative bacteria, including multidrug-resistant pathogens, but they do not provide persistent antimicrobial effect (approximately 1 to 3 hours of effect). ${ }^{19}$ Chlorhexidine gluconate causes 
Table 3. Wound Classification and Infection Risk $\mathbf{k}^{3,9}$

\begin{tabular}{|c|c|c|}
\hline Wound Classification & Description & $\begin{array}{l}\text { Risk of Surgical } \\
\text { Site Infection, \% }\end{array}$ \\
\hline Clean & $\begin{array}{l}\text { Uninfected operative wound with no inflammation } \\
\text { Does not involve respiratory, alimentary, genital, or urinary tract }\end{array}$ & 1.76 \\
\hline Clean-contaminated & Operative wound involving the respiratory, alimentary, genital, or urinary tract & 3.94 \\
\hline Contaminated & $\begin{array}{l}\text { Open, fresh, accidental wound } \\
\text { Major breaks in sterile technique } \\
\text { Gross spillage from the gastrointestinal tract } \\
\text { Nonpurulent inflammation including necrotic tissue }\end{array}$ & 4.75 \\
\hline Dirty/infected & $\begin{array}{l}\text { Old, traumatic wounds with retained devitalized tissue } \\
\text { Clinical infection or perforated viscera }\end{array}$ & 5.16 \\
\hline
\end{tabular}

disruption of cytoplasmic membranes, is more effective against gram-positive than gram-negative bacteria, and is more effective than alcohol-based solutions. Although not as immediately effective as alcohol-based solutions, chlorhexidine gluconate lasts for at least 6 hours. ${ }^{19}$ lodophor/iodine scrubs cause impaired protein synthesis and alteration of cell membranes, provide rapid onset of action, and are effective against gram-positive and gram-negative bacteria. ${ }^{19}$ Alcohol-based scrubs with chlorhexidine provide the best immediate and persistent antimicrobial activity. A prewash with a nonantimicrobial soap and drying before applying the alcohol-based scrub is recommended. Even with appropriate washing, all skin flora and bacteria may not be removed. Additionally, bacteria reaccumulate over time-an especially important consideration during lengthy proceduresso double-gloving is recommended.

\section{Intraoperative Considerations}

Antibiotic Prophylaxis. Appropriate weight-based antibiotics should be administered prior to the start of surgery. According to the Clinical Practice Guidelines for Antimicrobial Prophylaxis in Surgery, cefazolin is a first-line recommended prophylactic antibiotic. ${ }^{20}$ The recommended dose is 2 grams for patients weighing $<120 \mathrm{~kg}$ and 3 grams for patients $\geq 120 \mathrm{~kg}$, administered up to 30 minutes prior to incision. ${ }^{20}$ For patients with a severe allergy to cefazolin, clindamycin or vancomycin plus an aminoglycoside, such as gentamicin, is recommended and can be administered up to 2 hours prior to incision. ${ }^{20}$ Alternatively, metronidazole plus an aminoglycoside or fluoroquinolone can be used. In addition to administering the appropriate antibiotics prior to surgery, care must be taken to readminister antibiotics when necessary. Because of the half-life of cefazolin, readministration is recommended 4 hours after the initial dose. The redosing interval for clindamycin is 6 hours. Redosing of gentamicin and vancomycin is not recommended. Redosing of antibiotics is also recommended in cases of excessive blood loss, defined as $\geq 1,500 \mathrm{~mL}$.

Skin Preparation in the Operating Room. Prior to making the surgical incision, the skin is cleaned to remove microorganisms. Several skin preparations are available, and they vary in onset of action, duration, and antimicrobial coverage (Table 4). ${ }^{21}$ Based on these factors, a solution of alcohol with chlorhexidine gluconate is preferred, such as ChloraPrep (2\% chlorhexidine gluconate and $70 \%$ isopropyl alcohol). ChloraPrep must be applied appropriately to ensure effectiveness and safety. ${ }^{22}$ The skin must be prepped for 30 seconds in dry areas and for 2 minutes in moist areas, such as underneath a pannus. To prevent fires in the operating room, the solution must be allowed to dry. In hairless areas, the recommended drying time is 3 minutes. In areas with hair, the recommended drying time is 1 hour.

Operating Room Environment. Perioperative hypothermia can increase the risk of SSI. Kurz et al found a

Table 4. Antiseptic Skin Preparations ${ }^{21}$

\begin{tabular}{|c|c|c|c|c|c|c|}
\hline Antiseptic & $\begin{array}{l}\text { Mechanism of } \\
\text { Action }\end{array}$ & $\begin{array}{l}\text { Antimicrobial } \\
\text { Coverage }\end{array}$ & Onset & Application & Duration & Examples \\
\hline $\begin{array}{l}\text { Aqueous- } \\
\text { iodophor }\end{array}$ & $\begin{array}{l}\text { Causes protein } \\
\text { damage and } \\
\text { DNA damage }\end{array}$ & $\begin{array}{l}\text { Gram positive, } \\
\text { gram negative, } \\
\text { fungi, viruses }\end{array}$ & Intermediate & $\begin{array}{l}\text { 2-step scrub and } \\
\text { paint }\end{array}$ & $2 \mathrm{~h}$ & $\begin{array}{l}\text { Betadine } \\
\text { Scrub Care }\end{array}$ \\
\hline Aqueous-CHG & $\begin{array}{l}\text { Disrupts } \\
\text { membrane }\end{array}$ & $\begin{array}{l}\text { Gram positive, } \\
\text { gram negative, } \\
\text { fungi, viruses }\end{array}$ & Intermediate & $\begin{array}{l}\text { 2-step scrub and } \\
\text { dry, repeat }\end{array}$ & $6 \mathrm{~h}$ & Hibiclens \\
\hline $\begin{array}{l}\text { Alcohol- } \\
\text { iodophor }\end{array}$ & $\begin{array}{l}\text { Denatures protein } \\
\text { and causes DNA } \\
\text { damage }\end{array}$ & Gram negative & Rapid & $\begin{array}{l}\text { 1-step paint, dry } \\
\text { time of } 3 \text { min in } \\
\text { hairless areas }\end{array}$ & $\begin{array}{l}48 \mathrm{~h} \\
96 \mathrm{~h}\end{array}$ & $\begin{array}{l}\text { DuraPrep } \\
\text { Prevail-FX }\end{array}$ \\
\hline Alcohol-CHG & $\begin{array}{l}\text { Denatures protein } \\
\text { and disrupts } \\
\text { membrane }\end{array}$ & Gram negative & Rapid & $\begin{array}{l}30 \text { s or } 2 \text { min, dry } \\
\text { time of } 3 \text { min in } \\
\text { hairless areas }\end{array}$ & $48 \mathrm{~h}$ & ChloraPrep \\
\hline
\end{tabular}

CHG, chlorhexidine gluconate. 
3-times increased risk of SSI in patients who became hypothermic $\left(34.5{ }^{\circ} \mathrm{C} / 94.1{ }^{\circ} \mathrm{F}\right)$ during elective colorectal resection for cancer or inflammatory bowel disease. ${ }^{23}$ This increased risk is attributable to decreased blood perfusion that decreases antibiotic penetration into the subcutaneous and adipose tissue. Hypothermia also increases blood loss, decreases wound healing, and increases cardiac morbidity. ${ }^{24,25}$ Normothermia is defined as a core temperature of at least $36{ }^{\circ} \mathrm{C}$ on arrival to the postanesthesia care unit. ${ }^{26}$

\section{Postoperative Considerations}

Surgical Site Dressing. A 2016 Cochrane review demonstrated that no one dressing was superior for prevention of $\mathrm{SSI}^{27}$ so consensus is lacking on what type of dressing is best for prevention of SSI. However, the CDC recommends that the dressing remain in place for 24 to 48 hours after surgery. ${ }^{28}$

Vacuum-Assisted Wound Closure. Prophylactic vacuumassisted wound closure has been shown to reduce the risk of SSI in patients who undergo cesarean section. ${ }^{29}$ In a 2019 Cochrane review, using a negative pressure vacuum for primary wound closure was associated with a decreased incidence of SSI compared to routine dressing in the general, orthopedic, and obstetric surgical units in acute care hospitals. ${ }^{30}$ Although the review was not specific to gynecologic surgery, the results demonstrated in other types of surgery are promising. More studies are needed to determine if prophylactic vacuum application is a cost-effective means of reducing SSIs in gynecologic surgeries with abdominal incisions.

Patient Instructions. Patients need to be engaged in preventing SSIs. A review conducted by Tartari et al, based on current recommendations and an expert panel, demonstrated that patient instructions should address hair removal, smoking cessation, preoperative showering, and wound care after surgery. ${ }^{31}$ Postoperative instructions must be appropriate to the health literacy of the patients receiving them. $^{32}$

\section{SURGICAL BUNDLES}

Implementation of surgical care bundles has been shown to reduce SSI rates in colorectal surgery, ${ }^{33}$ orthopedic surgery, ${ }^{34}$ and spinal surgery. ${ }^{35}$ The Council on Patient Safety in Women's Health Care created a bundle to prevent SSIs specific to gynecologic surgery. ${ }^{36}$ The prevention of surgical site infections after major gynecologic surgery bundle is divided into 4 sections: readiness, recognition and prevention, response, and reporting and systems learning. The readiness section calls for all facilities to implement preoperative and intraoperative best practices as well as a team approach to preventing SSIs. The recognition section addresses assessment of modifiable and nonmodifiable patient risk factors for every patient. The response section suggests intraoperative timeouts to address patient-specific issues, as well as reassessment of patient risk. The reporting and systems learning section focuses on collecting, analyzing, and sharing data. To achieve success, however, quality improvement techniques and tools are needed to augment the best practice recommendations of the bundle. The bundle, combined with improvement in science, can improve SSI rates.

\section{CONCLUSION}

Some risk factors for SSI are modifiable, and best practices should be established and followed to reduce those risks. While several preoperative, intraoperative, and postoperative best practices have been demonstrated to reduce the risk of SSIs, research is still needed to determine best practices for some aspects of the surgical process. Using a bundled approach in conjunction with quality improvement tools can make a positive impact in the reduction of SSIs.

\section{ACKNOWLEDGMENTS}

The author has no financial or proprietary interest in the subject matter of this article.

\section{REFERENCES}

1. Reichman DE, Greenberg JA. Reducing surgical site infections: a review. Rev Obstet Gynecol. 2009;2(4):212-221.

2. Shepard J, Ward W, Milstone A, et al. Financial impact of surgical site infections on hospitals: the hospital management perspective. JAMA Surg. 2013;148(10):907-914. doi: 10.1001/jamasurg.2013.2246

3. Surgical site infection (SSI) event. Centers for Disease Control and Prevention. January 2018. Accessed November 16, 2020. www.cdc.gov/nhsn/pdfs/pscmanual/9pscssicurrent.pdf

4. Ban KA, Minei JP, Laronga C, et al. American College of Surgeons and Surgical Infection Society: surgical site infection guidelines, 2016 update. J Am Coll Surg. 2017;1:59-74. doi: 10.1016/j.jamcollsurg.2016.10.029

5. About strong for surgery. American College of Surgeons. 2017. Accessed December 27, 2018. www.facs.org/quality-programs/strong-for-surgery/about

6. Winfield RD, Reese S, Bochicchio K, Mazuski JE, Bochicchio GV. Obesity and the risk for surgical site infection in abdominal surgery. Am Surg. 2016;82(4):331-336.

7. Pop-Vicas A, Musuuza JS, Schmitz M, Al-Niaimi A, Safdar N. Incidence and risk factors for surgical site infection post-hysterectomy in a tertiary care center. Am J Infect Control. 2017;45(3):284-287. doi: 10.1016/j.ajic.2016.10.008

8. Mazzeffi M, Tanaka K, Galvagno S. Red blood cell transfusion and surgical site infection after colon resection surgery: a cohort study. Anesth Analg. 2017;125(4):1316-1321. doi: 10.1213/ANE.0000000000002099

9. Ortega G, Rhee DS, Papandria DJ, et al. An evaluation of surgical site infections by wound classification system using the ACS-NSQIP. J Surg Res. 2012;174(1):33-38. doi: $10.1016 /$ j.jss.2011.05.056

10. Webster J, Osborne S. Preoperative bathing or showering with skin antiseptics to prevent surgical site infection. Cochrane Database Syst Rev. 2015;(2):CD004985. doi: 10.1002/14651858.CD004985.pub5

11. Edmiston CE Jr, Lee CJ, Krepel CJ, et al. Evidence for a standardized preadmission showering regimen to achieve maximal antiseptic skin surface concentrations of chlorhexidine gluconate, $4 \%$, in surgical patients. JAMA Surg. 2015;150(11):1027-1033. doi: 10.1001/jamasurg.2015.2210. Erratum in Incomplete disclosure of potential conflicts of interest. JAMA Surg. 2016;151(3):297. doi: 10.1001/jamasurg.2015.5589

12. Duggan EW, Carlson K, Umpierrez GE. Perioperative hyperglycemia management: an update. Anesthesiology. 2017;126(3):547-560. doi: 10.1097/ALN.0000000000001515. Erratum in Perioperative hyperglycemia management: an update: erratum. Anesthesiology. 2018;129(5):1053. doi: 10.1097/ALN.0000000000002425 
13. Joshi GP, Chung F, Vann MA, et al. Society for Ambulatory Anesthesia consensus statement on perioperative blood glucose management in diabetic patients undergoing ambulatory surgery. Anesth Analg. 2010;111(6):1378-1387. doi: 10.1213/ANE.0b013e3181f9c288

14. Moghissi ES, Korytkowski MT, DiNardo M, et al. American Association of Clinical Endocrinologists and American Diabetes Association consensus statement on inpatient glycemic control. Endocr Pract. 2009;15(4):353-369. doi: 10.4158/EP09102.RA

15. Umpierrez GE, Hellman R, Korytkowski MT, et al. Management of hyperglycemia in hospitalized patients in non-critical care setting: an Endocrine Society clinical practice guideline. J Clin Endocrinol Metab. 2012;97(1):16-38. doi: 10.1210/jc.2011-2098

16. Lazar HL, McDonnell M, Chipkin SR, et al. The Society of Thoracic Surgeons practice guideline series: blood glucose management during adult cardiac surgery. Ann Thorac Surg. 2009;87(2):663-669. doi: 10.1016/j.athoracsur.2008.11.011

17. Berríos-Torres SI, Umscheid CA, Bratzler DW, et al. Centers for Disease Control and Prevention guideline for the prevention of surgical site infection, 2017. JAMA Surg. 2017;152(8):784-791. doi: 10.1001/jamasurg.2017.0904. Erratum in Corrections to numbering, abstract, and methods. JAMA Surg. 2017;152(8):803. doi: 10.1001/jamasurg.2017.1943

18. Duncan AE. Hyperglycemia and perioperative glucose management. Curr Pharm Des. 2012;18(38):6195-6203. doi: $10.2174 / 138161212803832236$

19. Boyce JM, Pittet D; Healthcare Infection Control Practices Advisory Committee; HICPAC/SHEA/APIC/IDSA Hand Hygiene Task Force. Guideline for hand hygiene in health-care settings. Recommendations of the Healthcare Infection Control Practices Advisory Committee and the HICPAC/SHEA/APIC/IDSA Hand Hygiene Task Force. Society for Healthcare Epidemiology of America/Association for Professionals in Infection Control/Infectious Diseases Society of America. MMWR Recomm Rep. 2002;51(RR-16):1-45, quiz CE1-4.

20. Bratzler DW, Dellinger EP, Olsen KM, et al. Clinical practice guidelines for antimicrobial prophylaxis in surgery. Surg Infect (Larchmt). 2013;14(1):73-156. doi: 10.1089/sur.2013.9999

21. Hemani ML, Lepor H. Skin preparation for the prevention of surgical site infection: which agent is best? Rev Urol. 2009;11(4):190-195.

22. ChloraPrep ${ }^{\circledast} 26 \mathrm{~mL}$ applicator: patient preoperative skin preparation. $2 \%$ chlorhexidine gluconate (CHG) and $70 \%$ isopropyl alcohol (IPA). 2013. Becton, Dickinson and Company. Accessed December 30, 2018. www.bd.com/documents/inservice-materials/IP_ChloraPrep-26mL-Poster_IM_EN.pdf

23. Kurz A, Sessler DI, Lenhardt R. Perioperative normothermia to reduce the incidence of surgical-wound infection and shorten hospitalization. Study of wound infection and temperature group. NEngl J Med. 1996;334(19):1209-1215. doi: 10.1056/NEJM199605093341901

24. Rajagopalan S, Mascha E, Na J, Sessler DI. The effects of mild perioperative hypothermia on blood loss and transfusion requirement. Anesthesiology. 2008;108(1):71-77. doi: 10.1097/01.anes.0000296719.73450.52

25. Sessler DI. Perioperative thermoregulation and heat balance. Lancet. 2016;387(10038):2655-2664. doi: 10.1016/S0140-6736(15)00981-2

26. Hopf HW. Perioperative temperature management: time for a new standard of care? Anesthesiology. 2015;122(2):229-230. doi: 10.1097/ALN.0000000000000552

27. Dumville JC, Gray TA, Walter CJ, et al. Dressings for the prevention of surgical site infection. Cochrane Database Syst Rev. 2016;12(12):CD003091. doi: 10.1002/14651858.CD003091.pub4

28. Top CDC recommendations to prevent healthcare-associated infections. Centers for Disease Control and Prevention. 2017. Accessed December 30, 2018. www.cdc.gov/HAl/pdfs/hai/ top-cdc-recs-factsheet.pdf

29. Echebiri NC, McDoom MM, Aalto MM, Fauntleroy J, Nagappan $\mathrm{N}$, Barnabei VM. Prophylactic use of negative pressure wound therapy after cesarean delivery. Obstet Gynecol. 2015;125(2):299-307. doi: 10.1097/AOG.0000000000000634. Erratum in Obstet Gynecol. 2015;126(4):903.

30. Webster J, Liu Z, Norman G, et al. Negative pressure wound therapy for surgical wounds healing by primary closure. Cochrane Database Syst Rev. 2019;3(3):CD009261. doi: 10.1002/14651858.CD009261.pub4

31. Tartari $E$, Weterings V, Gastmeier $P$, et al. Patient engagement with surgical site infection prevention: an expert panel perspective. Antimicrob Resist Infect Control. 2017;6:45. doi: 10.1186/s13756-017-0202-3

32. De Oliveira GS Jr, McCarthy RJ, Wolf MS, Holl J. The impact of health literacy in the care of surgical patients: a qualitative systematic review. BMC Surg. 2015;15:86. doi: 10.1186/s12893-015-0073-6

33. Tanner J, Padley W, Assadian O, Leaper D, Kiernan M, Edmiston C. Do surgical care bundles reduce the risk of surgical site infections in patients undergoing colorectal surgery? A systematic review and cohort meta-analysis of 8,515 patients. Surgery. 2015;158(1):66-77. doi: 10.1016/j.surg.2015.03.009

34. Schriefer J, Hilt S, Sanders J, et al. Implementation of a pediatric orthopaedic bundle to reduce surgical site infections. Orthop Nurs. 2017;36(1):49-59. doi: 10.1097/NOR.0000000000000312. Erratum in Implementation of a pediatric orthopaedic bundle to reduce surgical site infections: erratum. Orthop Nurs. 2017 Mar/Apr;36(2):130. doi: 10.1097/01.NOR.0000515820.05546.be

35. Anderson PA, Savage JW, Vaccaro AR, et al. Prevention of surgical site infection in spine surgery. Neurosurgery. 2017;80(3S):S114-S123. doi: 10.1093/neuros/nyw066

36. Pellegrini JE, Toledo P, Soper DE, et al. Consensus bundle on prevention of surgical site infections after major gynecologic surgery. Obstet Gynecol. 2017;129(1):50-61. doi: 10.1097/AOG.0000000000001751. Erratum in National Partnership for Maternal Safety Consensus Bundles: correction. Obstet Gynecol. 2019;133(6):1287. doi: 10.1097/AOG.0000000000003292

This article meets the Accreditation Council for Graduate Medical Education and the American Board of Medical Specialties Maintenance of Certification competencies for Patient Care and Medical Knowledge.

(C2020 by the author(s); licensee Ochsner Journal, Ochsner Clinic Foundation, New Orleans, LA. This article is an open access article distributed under the terms and conditions of the Creative Commons Attribution (CC BY) license (creativecommons.org/licenses/by/4.0/legalcode) that permits unrestricted use, distribution, and reproduction in any medium, provided the original author(s) and source are credited. 